\title{
COMPLICATIONS OF COLOSTOMY AFTER COLORECTAL SURGERY
}

\author{
By
Ahmed Abd El-Wakeel Abd El-Aal Saied, Saied Hosny Bendary and Ayman Mohammed Abdul-mohaymen \\ Department of Surgical Oncology, Faculty of Medicine- Al-Azhar University \\ Corresponding author: Ahmed Abdel Wakeel Abdel-Aal Saied, \\ Mobile: 01144325292, E-mail: ahmedabdelwakee189@gmail.com
}

\begin{abstract}
Background: Significant morbidity is associated with stoma creation and these complications can be grouped into early and late-occurring complications. The literature reports the rate of stoma-related complications ranging from 20 to $70 \%$. Early complications occur within the first 30 days of the stoma creation and include ischemia/necrosis, retraction, mucocutaneous separation, and parastomal abscess.
\end{abstract}

Objective: To evaluate complications of stoma after colorectal surgeries, both early and late complications of colostomy were assessed with respect to the frequency of complications, health-related quality of life (QoL), and length of hospitalization (LoH).

Patients and Methods: This was a randomized prospective trial evaluating early and late complications of colostomy after colorectal surgeries in Department of Surgical Oncology, Al-Azhar University Hospital. This study was started at June 2017 and ended at May 2019. Patients were included after they agree to be included in the study and an informed consent was taken. Screening for and inclusion of participants was made after the index surgery. Follow-up of patients was at the time of surgery and up to 6 months after index surgery. Fifty patients were included in this study and assessment of early and late complications was done. The risk of postoperative complications is dependent on patient-related factors and technical aspects of the operative procedure.

Results: Retraction was found to be the most common complication (16\% of all patients). Parastomal herniation was the most common late complication after colostomy creation and it affected about $16 \%$ of all patients.

Conclusion: Complications from colostomies are frequent, costly, and difficult to resolve, even after multiple operations. Prevention of complications occurred through sufficient time spent in siting and mobilization, with strict attention to detail and a meticulous technique.

Keywords: Stoma, rectal cancer, colorectal surgery, pyoderma gangrenosum.

\section{INTRODUCTION}

Colostomy-related complications are common and affect between 11 and 69\% of all colostomies (Mahjoubi et al., 2015).

Statistically; 15 up to $48 \%$ of colostomies are either planned or remain permanent, and the occurrence of complications in these patients has significant negative implications for their quality of life (Arumugam et al., 2013).

Colostomy complications may be conveniently classified into those occurring in the early post-operative period (within 30 days), and those occurring later, although there is overlap in some cases (Atkin et al., 2015). 
Early complications occur in 22 to $68 \%$ of patients and include stomal ischemia and necrosis, retraction, parastomal infection, dermatological complications, and problems relating to poor siting of the stoma (Mylonakis et al., 2011).

Late complications occur in up to $58 \%$ of patients and commonly include parastomal herniation, prolapse, stenosis, and dermatological complications (Law et al., 2012).

In almost $10 \%$ of patients, more than one late complication develops, and up to one-third of complications require revisional surgery (Carne et al., 2013).

The aim of the present work was to evaluate early and late complications of colostomy after colorectal surgery.

\section{PATIENTS AND METHODS}

This was a randomized prospective trial evaluating early and late complications of colostomy after colorectal surgeries in Department of Surgical Oncology, Al Azhar University Hospital. This study was started at June 2017 and ended at May 2019. Screening for and inclusion of participants was made after the index surgery. Follow-up of patients was at the time of surgery and up to 6 months after index surgery. Patients were included after they agreed to be included in the study and informed consent were taken.

\section{Participants:}

Patients eligible for enrolment into this study were $>16$ and $<70$ years of age and had all received surgical treatment (colorectal surgeries ended up with colostomy).

\section{Inclusion criteria:}

Patients underwent colorectal surgeries with stoma creation, Age between 16 and 75 years old.

\section{Exclusion criteria:}

Patients with advanced disease (Obstructed and Perforated tumors), patients unfit for surgery and patients refusing surgery.

During the first days following surgery, the patients underwent an individual assessment and screening process describing their postsurgical state. The assessment was carried out, and the patients were categorized and scored regarding bowel function, functional level of nutrition and mobilization.

The second examination was carried out 3 days after surgery and stated if the stoma is viable, functioning, spouting not retracted. The general condition and mobility of the patient was also assessed.

\section{Preoperative workup:}

\section{Full history taking.}

\section{Physical examination.}

3. Laboratory investigations: Blood sampling for pre-operative laboratory tests; CBC, bleeding profile (PT, PTT \& INR). Liver function tests (ALT, AST \& albumin). Renal function tests (serum urea $\&$ creatinine).

4. Imaging: Chest X-ray, Pelviabdominal ultrasound and Computed tomography (CT) scanning of the abdomen and pelvis with intravenous and rectal contrast. In malignant lesions, CT scanning demonstrates the degree of local spread, attachment to 
nearby structures, peritoneal deposits and the presence of hepatic metastasis.

\section{Lower GI endoscopy and tissue biopsy.}

\section{Post-operative workup:}

Hospital stay, postoperative complications, histopathological findings and follow up for six months.

\section{Statistical methods:}

Data were coded and entered using the statistical package SPSS version 25. Data were summarized using mean, standard deviation and range for quantitative variables and frequencies (number of cases) and relative frequencies (percentages) for categorical variables.

\section{RESULTS}

We included 50 cases in this research. This group included 34 males $(68 \%)$ and 16 females (32\%) (Table 1). The mean age of the study was 55.88 ranging from 30 to 68 years old with standard deviation of 10.39 (Table 2).

Table (1): Sex variation of the studied group

\begin{tabular}{|c|c|c|c|}
\hline Parameter & Count & Number of cases ( for total of 50) & Percentage \\
\hline \multirow{2}{*}{ Sex } & F & 16 & $32.0 \%$ \\
\cline { 2 - 4 } & M & 34 & $68.0 \%$ \\
\hline
\end{tabular}

Table (2): Age of the studied group

\begin{tabular}{|c|c|c|c|c|}
\hline Count & Mean & $\begin{array}{c}\text { Standard } \\
\text { Deviation }\end{array}$ & Minimum & Maximum \\
\hline Age & 55.88 & 10.39 & 30.00 & 68.00 \\
\hline
\end{tabular}

As regarding complications of stoma, $28 \%$ of all patients reported early complications of stoma after colorectal surgeries. $12 \%$ of the patients were found to have ischemic changes; the same patients reported necrosis as early complications.

$16 \%$ of the patients reported retraction of the stoma. Parastomal infection was reported in $14 \%$ of the patients (Table 3 ).

Table (3): Early complications of stoma

\begin{tabular}{|l|c|c|c|}
\hline \multirow{2}{*}{ Parameters } & Count & $\begin{array}{c}\text { Number of } \\
\text { cases }\end{array}$ & $\%$ \\
\hline \multirow{2}{*}{ Early complications } & Yes & 14 & $28.0 \%$ \\
\cline { 2 - 4 } & No & 36 & $72.0 \%$ \\
\hline \multirow{2}{*}{ Ischemia } & Yes & 6 & $12.0 \%$ \\
\cline { 2 - 4 } & No & 44 & $88.0 \%$ \\
\hline \multirow{2}{*}{ Necrosis } & Yes & 6 & $12.0 \%$ \\
\cline { 2 - 4 } & No & 44 & $88.0 \%$ \\
\hline \multirow{2}{*}{ Retraction } & Yes & 8 & $16.0 \%$ \\
\cline { 2 - 4 } & No & 42 & $84.0 \%$ \\
\hline \multirow{2}{*}{ Parastomal infection } & Yes & 7 & $14.0 \%$ \\
\hline \multirow{2}{*}{$\begin{array}{l}\text { Early dermatological } \\
\text { complications }\end{array}$} & No & 43 & $86.0 \%$ \\
\cline { 2 - 4 } & Yes & 4 & $8.0 \%$ \\
\cline { 2 - 4 } & No & 46 & $92.0 \%$ \\
\hline
\end{tabular}


$32 \%$ of all cases were found to have late complications. $16 \%$ of them reported parastomal herniation. $44 \%$ patients reported prolapse of the stoma. Stenosis was reported in $4 \%$ of them (Table 4).

Table (4): Late complications of stoma

\begin{tabular}{|c|c|c|c|}
\hline \multirow{2}{*}{ Parameters } & Count & \multirow{2}{*}{ Count } & \% \\
\hline \multirow{2}{*}{ Late complications } & Yes & 16 & $32.0 \%$ \\
\cline { 2 - 4 } & No & 34 & $68.0 \%$ \\
\hline \multirow{2}{*}{ Parastomal hernia } & Yes & 8 & $16.0 \%$ \\
\cline { 2 - 4 } & No & 42 & $84.0 \%$ \\
\hline \multirow{2}{*}{ Prolapse } & Yes & 8 & $16.0 \%$ \\
\cline { 2 - 4 } & No & 42 & $84.0 \%$ \\
\hline \multirow{2}{*}{ Stenosis } & Yes & 2 & $4.0 \%$ \\
\cline { 2 - 4 } & No & 48 & $96.0 \%$ \\
\hline \multirow{2}{*}{$\begin{array}{c}\text { Late dermatological } \\
\text { complications }\end{array}$} & Yes & 1 & $2.0 \%$ \\
\cline { 2 - 4 } & No & 49 & $98.0 \%$ \\
\hline
\end{tabular}

\section{DISCUSSION}

The stoma is the common surgical condition for general surgeons. The word "Stoma" comes from the Greek word meaning mouth or opening, Stomas are used to divert the fecal stream away from distal bowel in order to allow a distal anastomosis to heal as well as to relieve obstruction in emergency situation. It may be temporary or permanent; depending on their role (Rovena et al., 2019). Though a lifesaving procedure, it may result in significant number of complications. Complications are divided into early complications (up to 30 days after operation) and late complications (more than 30 days after operation) (Ahmad and Apoorv, 2013).

On analysis of our findings, we found that out of our sample; $(68 \%)$ were males and $(32 \%)$ were females, and the mean age of the study was 55.88 ranging from 30 to 68 years old with standard deviation of 10.39 .

Qureshi et al., (2018) compared general and stoma specific complications in patients having stoma surgery in either an emergency or elective setting during their index hospital admission, and reported that the mean age was $63 \pm 21$ years in the emergency cohort and $57 \pm 19$ years in the elective cohort, and there were 102 females and 93 males.

Complications of stoma rates obviously also vary depending on the circumstances surrounding stoma creation. Although it seems intuitive that emergency operations with gross peritoneal soiling, gangrenous or perforated intestine, and creation of stomas in debilitated or malnourished patients would be associated with increased postoperative morbidity. This has not been borne out in the study of Choudhury et al. (2018). The very common complications of stoma creation included improper selection of site, vascular complications, retraction, peristomal skin irritation, peristomal infection/abscess/fistula, parastomal herniation, and postoperative bowel obstruction (Kwiatt and Kawata, 2013). 
Furthermore; as regard complications of stoma, the current study illustrated that $28 \%$ of all patients reported early complications of stoma after colorectal surgeries. $12 \%$ of the patients were found to have ischemic changes. The same patients reported necrosis as early complications, and $16 \%$ of the patients reported retraction of the stoma, while parastomal infection was reported in $14 \%$ of the patients.

In agreement with our study, the study done by Mirnezami et al. (2012) showed that early complications were found to occur in $68 \%$ of patients and include stomal ischemia and necrosis, retraction, parastomal infection and dermatological complications. Colostomy ischemia and necrosis usually develop within 24 hours of surgery and can occur in 1 to $14 \%$ of all colostomies. Several complications may occur after formation of a stoma, such as parastomal herniation, dermatitis, necrosis, parastomal fistula and abscesses, high stoma output and retraction (Steinhagen et al., 2017).

Various studies have been published reporting on stoma complications. Most of these studies demonstrated a high overall incidence of stoma-related complications, varying between $10 \%$ and $70 \%$ depending on the number of complications scored. Other studies focused on risk factors of stoma complications. The majority of information is incomplete or based on retrospective data analysis. This may cause under-registration of complications in most studies (Malik et al., 2018).

The complications vary depending on type of stoma. Patient-related factors, such as cardiovascular morbidity and obesity, increase the likelihood of a stomal complication. Ischemia and necrosis of a stoma are early complications. It is more common following colostomy formation than ileostomy (Pine and Stevenson et al., 2017).

On the other hand, the present study assessed the late complications which have been done among our participants, and demonstrated that $32 \%$ of all cases were found to have late complications. 16 $\%$ of them reported parastomal herniation. $44 \%$ patients reported prolapse of the stoma. Stenosis was reported in $4 \%$ of them.

Parastomal hernia is the most common complication in various types of stomas. It can progress almost asymptomatically, often resulting only in an abdominal deformity in the vicinity of the stoma, but in extreme cases it can lead to bowel incarceration and strangulation, thus necessitating immediate surgery. It is estimated that at present, approximately 1 in 3 patients suffering from this complication are treated surgically, which is partly explained by the high recurrence rate observed after repair. This led to the emergence of the concept of primary prevention using prosthetic mesh, particularly since many experts claim that the incidence of parastomal hernia is practically unavoidable and to a considerable extent simply a matter of time (Styliński et al., 2018).

Liu et al. (2012) reported in their study that common long-term complications included hernia, urinary retention, hemorrhage, skin conditions, and intestinal obstruction. Ostomy was associated with long-term fistula (odds ratio 5.4; 95\% CI 1.4-21.2), and among ostomy survivors, fistula was associated 
with reduced health-related quality of life $(\mathrm{p}<0.05)$, older survivors and survivors with severe systemic disease (American Society for Anesthesiologists grade 3) were at increased risk of hernia and other complications.

In a study done by Pine and Stevenson et al. (2017), it was found that complications of intestinal stomas occur in around $34 \%$ of patients. A significant proportion of these will require revisional surgery.

Finally, we reached to that surgery of performing a stoma and its postoperative complications are more common. These affect patient's quality of life and sense of well-being, while burdening the health care system. Very good care and meticulous attention to advanced technical detail should be executed to reduce the likelihood of postoperative complications and optimize stoma function. A prospective clinical trial including a complete evaluation of stoma- related and reversal complications is suggested, also we recommend for further prospective studies to assess the relationships between demographic and clinical factors and ostomy complications to improve care.

\section{CONCLUSION}

Complications from colostomies are frequent, costly, and difficult to resolve, even after multiple operations. Prevention of complications through sufficient time spent in siting and mobilization, with strict attention to detail and a meticulous technique, assume utmost importance. As regards early complications, retraction was found to be the most common complication. It affected about $16 \%$ of all patients. Parastomal herniation was the most common late complication after colostomy creation and it affected about $16 \%$ of all patients. This is often as a consequence of an excessively large fascial opening.

\section{REFERENCES}

1. Ahmad $Z$ and Apoorv S A (2013): Clinical study of intestinal stomas: its indications and complications. International Journal of Research in Medical Sciences, 1(4):536-540.

2. Arumugam PJ, Bevan $L$ and Macdonald L. (2013): A prospective audit of stomasanalysis of risk factors and complications and their management. Colorectal Dis; 5(1):4952.

3. Atkin G, Scott MA and Mathur P. (2015): The rectus sling to prevent loop colostomy retraction: a case series. Int Semin Surg Oncol; 2:22-24.

4. Carne PW, Robertson GM and Frizelle FA. (2013): Parastomal hernia. Br J Surg; 90(7):784-79

5. Choudhury CR, Bhutia TD and Bose B. (2018): A study of complications of temporary ileostomy in cases of acute abdomen with ileal perforation and obstruction. International Surgery Journal, 5:2349-2902

6. Kwiatt, M. and Kawata, M. (2013): Avoidance and management of stomal complications. Clinics in Colon and Rectal Surgery, 26(2):112-121.

7. Law WL, Chu KW and Choi HK. (2012): Randomized clinical trial comparing loop ileostomy and loop transverse colostomy for faecal diversion following total mesorectal excision. Br J Surg; 89(6):704-708.

8. Liu, L., Herrinton, L. J., Hornbrook, M. C., Wendel, C. S., Grant, M., \& Krouse, R. S. (2012): Early and late complications among long-term colorectal cancer survivors with ostomy or anastomosis. Diseases of The Colon and Rectum, 53(2): 200-212.

9. Mahjoubi B, Moghimi A and Mirzaei R. (2015): Evaluation of the end colostomy complications and the risk factors influencing 
them in Iranian patients. Colorectal Dis; 7(6):582-587.

10. Malik, T., Lee, M. J. and Harikrishnan, A. B. (2018): The incidence of stoma related morbidity - a systematic review of randomised controlled trials. Annals of the Royal College of Surgeons of England, 100(7): 501-508.

11. Mirnezami A.B, Brendan A, Alex S, and Moran J. (2012): Complications of Colostomy. Seminars in Colon and Rectal Surgery, 19:160-166.

12. Mylonakis E, Scarpa $M$ and Barollo $M$. (2011): Life table aanalysis of hernia following end colostomy construction. Colorectal Dis; 3(5):334-337.

13. Pine $\mathbf{J}$ and Stevenson $\mathbf{L}$ (2017): Intestinal stomas. Surgery (Oxford), 35(3):165-170.

14. Qureshi A, Cunningham J, Hemandas A. (2018): Elective vs. Emergency Stoma
Surgery Outcomes. World J Surg Surgical Res; 1: 1050-1062.

15. Rovena B, Virna $Z$, Lorenc $B$ and Hysni. (2019): A Clinical Study of Intestinal Stomas in Emergency Laparotomies, (35)2:21-23.

16. Steinhagen, E., Colwell, J. and Cannon, L. M. (2017): Intestinal Stomas-Postoperative Stoma Care and Peristomal Skin Complications. Clinics in Colon and Rectal Surgery, 30(3): 184-192.

17. Styliński, R., Alzubedi, A., and Rudzki, S. (2018): Parastomal hernia - current knowledge and treatment. Wideochirurgia i inne techniki maloinwazyjne = Videosurgery and other miniinvasive techniques, 13(1):1-8. 


\section{مضاعفات فتحة التبرز الجانبية بعد عمليات القولون والمستقيم}

أحمد عبد الوكيل عبد العال سعيد، سعيد حسني بنداري، أيمن محمد عبدالمهيمن

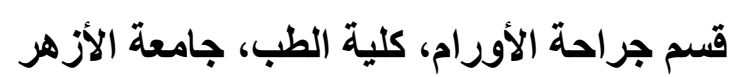

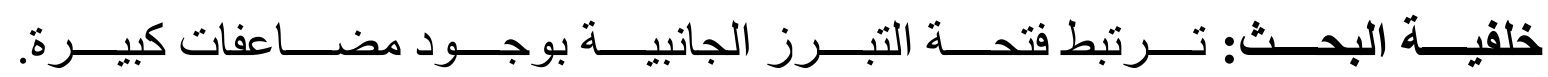

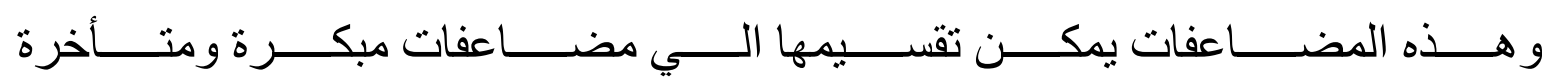

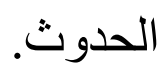

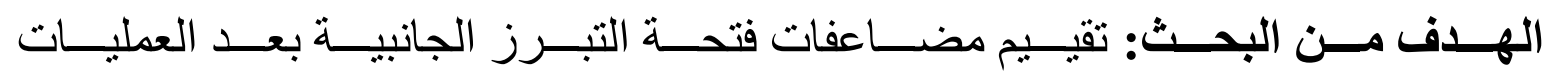

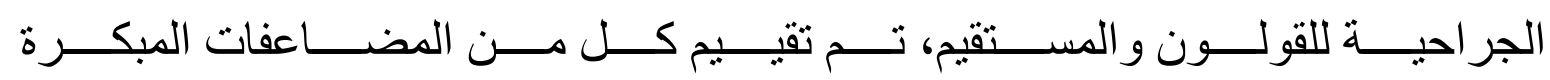

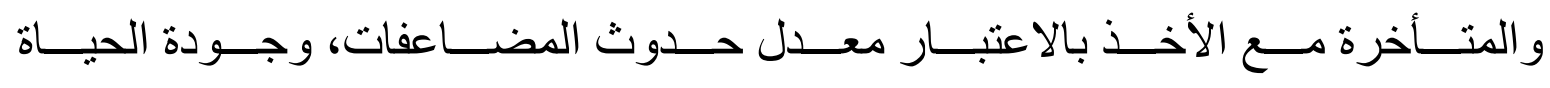
الصحية (QoL)، وطول الأقامة بالمستثفى (LoH).

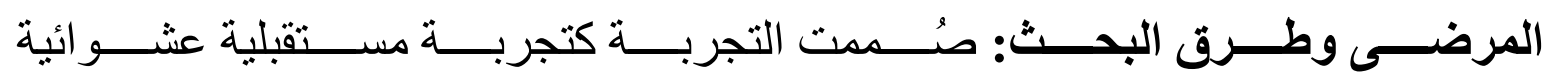

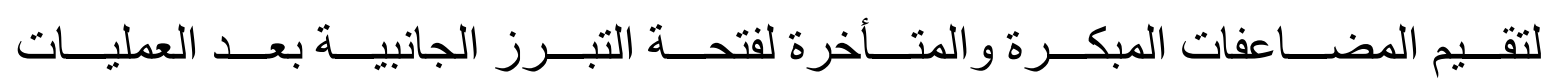

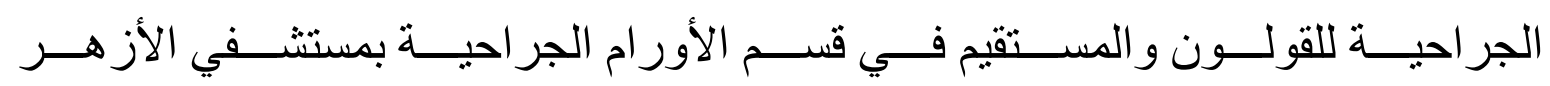

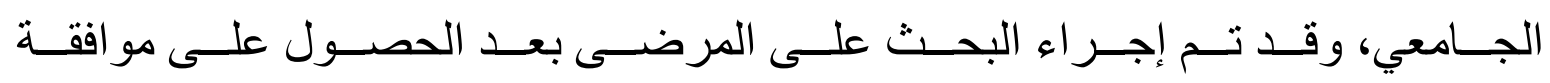

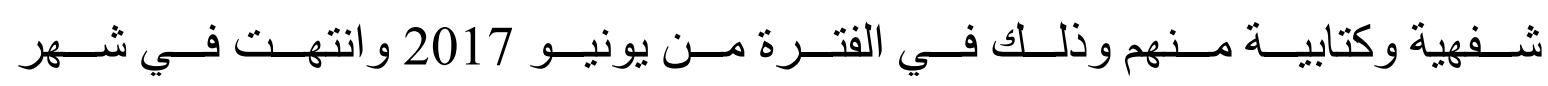

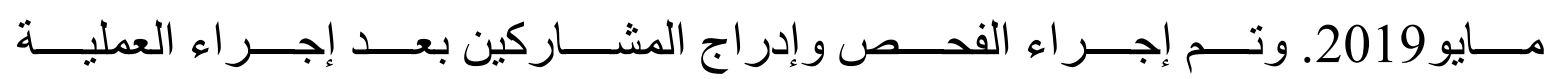

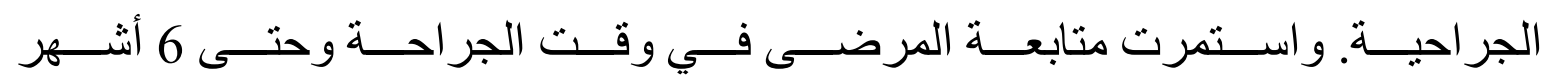

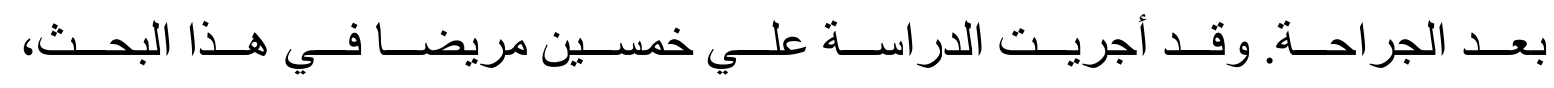

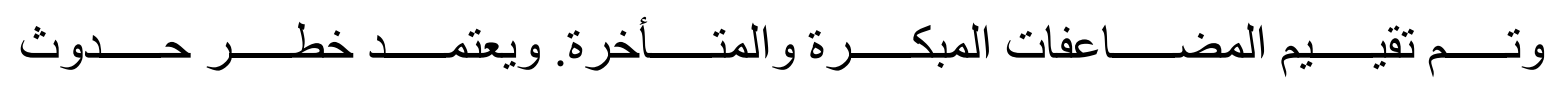

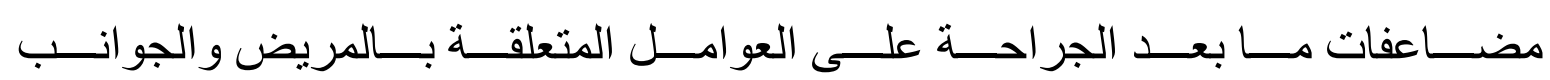

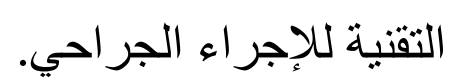

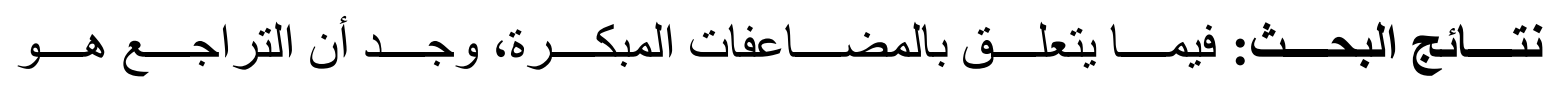

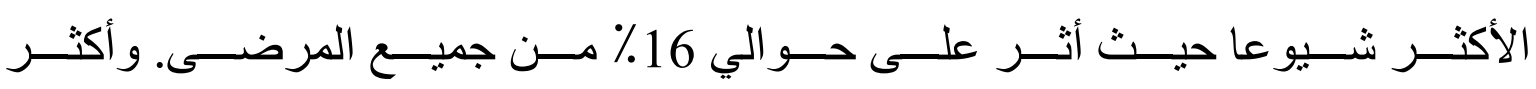




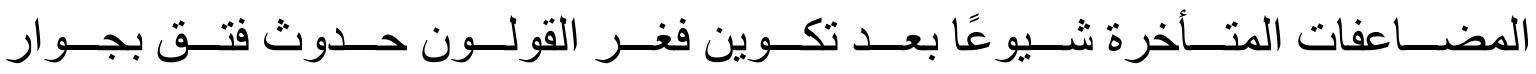
فتحة التبرز، وقد أثر على حوالي 16 ٪ من جميع المرضى.

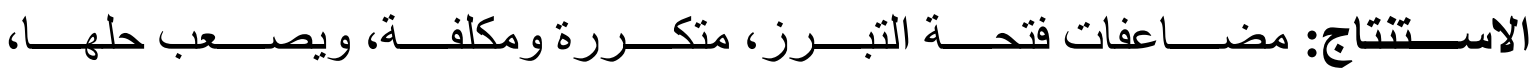

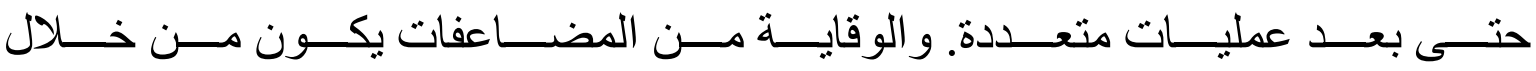

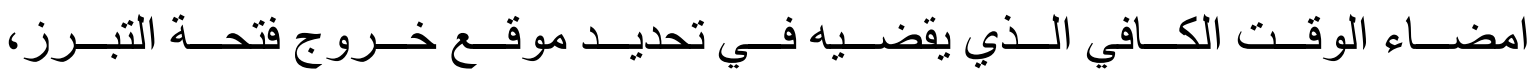
مع الاهتمام الصارم بالتفاصيل و التقنية الدقيقة التي تولي أهمية قصوى. 